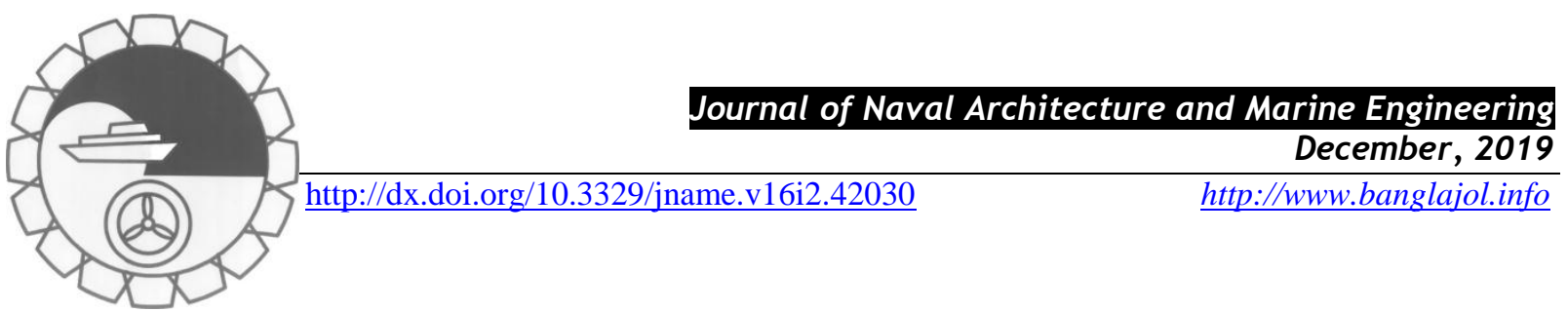

\title{
MEASUREMENT OF SMALL VESSEL MACHINERY VIBRATION INDUCED ACOUSTIC SIGNATURE LEVELS
}

GVV Pavan Kumar ${ }^{1 *}$, VVS Prasad $^{2}$ and BH Nagesh ${ }^{1}$

${ }^{1}$ School of Naval Architecture and Ocean Engineering, Indian Maritime University, Visakhapatnam Campus, India

*E-mail: gvvpavankumar@imu.ac.in

${ }^{2}$ Department of Marine Engineering, Andhra University, Visakhapatnam, India

\begin{abstract}
:
Ship vibrations, airborne and underwater noise levels have always been a challenging topic from performance point of view in ship design, building and operation. The measurement shall help in monitoring the self-noise and the technical state of their machinery mechanism. The vibration levels of the main engine and auxiliary Genset foundation, airborne noise levels of the engine room and underwater self-noise levels of a small mechanized fishing trawler was measured at the jetty in idling condition. The vibration levels on the foundation measured an average value of $0.207 \mathrm{~mm} / \mathrm{s}$ for main engine and $1.36 \mathrm{~mm} / \mathrm{s}$ for auxiliary Genset. The airborne noise levels measured $99 \mathrm{~dB}(A)$ in the engine room. The peak underwater sound pressure levels measured $162 \mathrm{~dB}$ re $1 \mu \mathrm{Pa}$. The response spectra indicate the peak vibration and noise levels in the lower frequency region $<1.2$ $\mathrm{kHz}$. The machinery excitation forces transferred to the hull surface as pressure fluctuations which generated the airborne and underwater noise levels. Though the measurement limited to jetty conditions, detailed analysis can be useful for detection, classification and tracking of small vessels.
\end{abstract}

Keywords: Small vessel, vibration, airborne, underwater noise levels and frequency.

\section{NOMENCLATURE}

$\begin{array}{llll}F W D & \text { Forward side of the vessel } & S L M & \text { Sound level meter } \\ A F T & \text { Aft side of the vessel } & S P L & \text { Sound Pressure level } \\ P O R T & \text { Port side of the vessel } & d B & \text { sound Pressure level } \\ \text { STBD } & \text { Starboard side of the vessel } & A B N & \text { Airborne noise } \\ V F H & \text { Visakhapatnam Fishing Harbor } & S B N & \text { Structure borne noise } \\ F F T & \text { Fast Fourier Transformation } & V & \begin{array}{l}\text { Vertical response of the machinery } \\ \text { foundation expressed in velocity }\end{array}\end{array}$

\section{Introduction}

Over the years there has been an effect of environmental impact due to man-made activities in water, for example, the oil and gas industry, renewable energy and transportation industry. The growth of the industries leads to serve negative consequences on the marine fauna (IQOE, 2018; Bosschers, 2017). The recent trends of ship design particularly in areas of structural optimization and reduction of environmental pollution have been a major concern to the designers (MEPC circular 833, 2014). The latest design standards, there is a tendency for noise and vibration issues to be addressed at the global level (McGoldrick, 1960). Ship design practice should always aim at heuristic deduction from previous designs and requires a sound engineering judgment Carlton and Vlasic (2005). The design criteria set should be considered in context of the whole design process to be realistic and achievable within the knowledge and engineering practice. The effects of noise and vibration need to be taken care in ship design with the recent innovation and development to provide healthy environment on-board (Nilsson, 1978; Lurton, 2002). The shipping traffic noise always hovers the ability of marine species to communicate, which vocalize at low frequency in the region, mostly close to vessel traffic movement (Putland et al., 2018; GVV P Kumar et al., 2019).

Among many, one of the major sources of underwater noise is due to ships movement. The dominant sources of vibration and noise on-board ship are the propeller, machinery and flow around the hull (American Bureau of 
Shipping, 2006; Gloza, 2011). The underwater noises radiated by ships have increased the ambient noise levels of the oceans. This increase has raised a warning alarm to reduce the ocean noise levels by implementing regulation like developing standards, the methodology for measurement, design modification for developing silent ships etc. (Mitson, 1995). This will help in developing a clam and healthy marine environment for the water species. The study can also be useful to enhance the small vessel security and safety based on the coherent framework in an innovative approach. The application of the passive acoustic methods for small vessel detection, classification and tracking in noisy environment was presented as DEMON acoustic signature, which were measured in distance up to $7 \mathrm{~km}$ Chung et al (2011).

The propeller is identified as a primary noise source transmits noise to the structure through the shaft line and through pressure field generated at the ship stern (Bosschers, 2017). The machinery radiated noise to the surrounding air as airborne noise $(\mathrm{ABN})$ and transmits the noise to the structure through its foundation as structure-borne noise $(\mathrm{SBN})$. The $\mathrm{ABN}$ is significant inside engine room and mainly affecting the neighboring compartments, transmitted through the deck and bulkheads. It also contributes to the transmission of noise to the water, through the ship hull and bottom structure. The SBN has been the object of most attention on the ship noise analysis point of view. Smaller vessel are medium speed engines with turbocharging and the noise levels emitted by these engines are higher when compared with low speed engines. In small ships the living compartments are much closer to the machinery spaces, it shall aggravates the noise levels in the vicinity Brooker and Humphrey (2015). Resilient mountings, isolation, acoustic and thermal insulation, deck covering and loading tank spaces help in dissipating the noise transmission (Ozsoysal, 2004). The modal analysis methods for estimating the energy delivers by the machinery to its foundation are the semi-empirical, Nilson's grillage methods and statistical energy analysis (Tratch, 1985); Gaggero et al (2014).

The present paper deals with the measurement results of underwater noise and machinery foundation vertical vibration levels and airborne noise levels of the engine room of a fishing trawler in idling condition with the main engine and Genset in operation at the jetty Holland and Wong (1995). The vibration response of the main engine is $0.331 \mathrm{~mm} / \mathrm{s}$ at $704 \mathrm{~Hz}$ and the auxiliary Genset is $3.13 \mathrm{~mm} / \mathrm{s}$ at $832 \mathrm{~Hz}$. The underwater sound pressure levels are $1 \mathrm{~dB}$ re $1 \mu \mathrm{Pa}$ at frequency $1.2 \mathrm{kHz}$ due to the machinery operation with spectrogram indicating the disturbance in the lower frequencies $<3 \mathrm{kHz}$. The engine room airborne noise levels are $100 \mathrm{~dB}$ (A) due to the machinery in operation. All the measured values are well within the acceptable limits as specified by the standards. However, the measurement has a limitation with regard to the jetty condition. The measured data helped to understand the machinery installation noise monitoring and the influence on the ambient noise levels of the region. The data shall be very useful to future studies for noise reduction and long-term measurement shall help in observing the changes in the ambient noise levels Kumar et al (2019).

\section{Experimental Measurements}

\subsection{Deployment location and vessel}

The measurements on a small mechanized fishing trawler was carried out at the Visakhapatnam Fishing Harbor (VFH) located in the east coast of India as indicated in Figure 1. The fishing harbor is located next to the Visakhapatnam Port entrance channel. The VFH is one of the biggest in the Andhra Pradesh coast spreading over 0.24 sq.km with around 11 jetties. There are around 700 boats operating regularly in the VFH. The average water depth of the VFH is $6 \mathrm{~m}$ and with max. Vessel draft $4 \mathrm{~m}$ is permitted to enter the VFH. There is continuous movement of fishing vessels operating in the harbor region. The fishing vessel in the present study is stern trawler shown in Figure 2, deployment by CIFNET (Central Institute of Fisheries Nautical and Engineering Training) deployed for regular fishing activity in the Visakhapatnam coast for training young cadets Aktas et al (2015). The vessel principal particulars are indicated in Table 1.

\subsection{Instrumentation and post-processing}

\section{a. Vibration}

The main engine and Genset foundation location as indicated in Figure 3. The measurement of the vibration levels in terms of velocity $(\mathrm{m} / \mathrm{s})$ was carried out using Bruel \& Kjaer vibration accelerometer type 4513 in Figure 4 with the specifications indicated in Table 2 and of frequency range $0-51.2 \mathrm{kHz}$ and LAN XI front-endpanel type 3056-A-040. These are modular analyzer with a flexible front-end for multi-channel and portable system aimed to monitor low-frequency voltage signal. The measurement is taken at the main engine and 
auxiliary. The post-processing of the measured signal was done using PULSE LabShop software for time domain and frequency spectrum (McGoldrick, 1960).

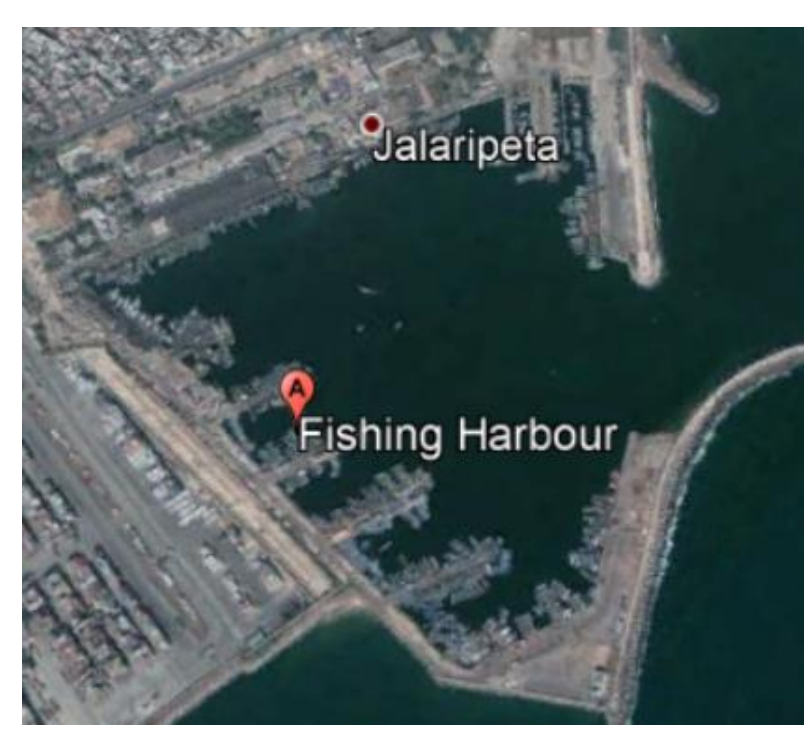

Figure 1: Visakhapatnam Fishing harbor layout as obtained from Google maps.

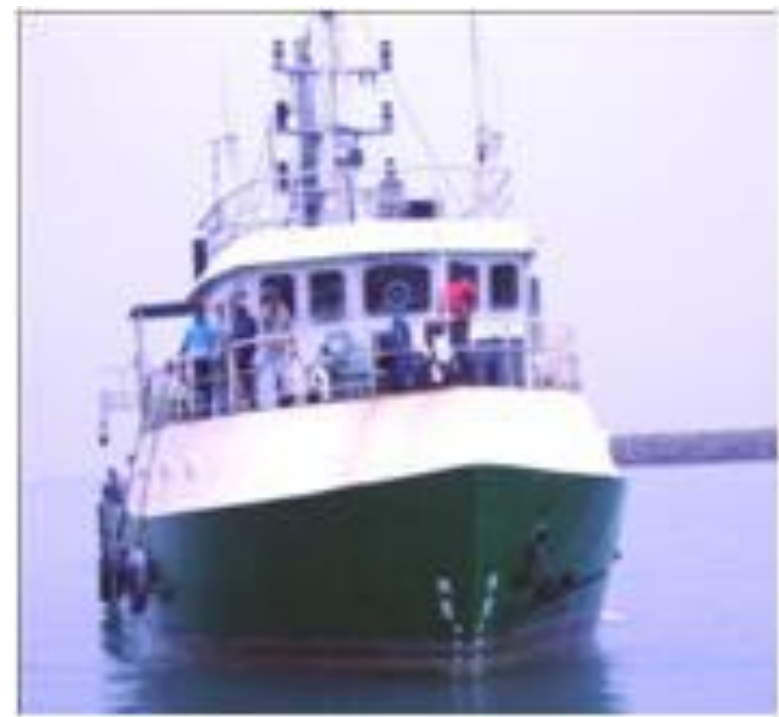

Figure 2: Fishing trawler MV Tharangini of Central Institute of Fisheries Nautical and Engineering Training (CIFNET), India.

Table 1: Fishing vessel specification

\begin{tabular}{|l|l|}
\hline Name of the vessel & MV Tharangini \\
\hline Type of vessel & Fishing vessel \\
\hline Length BP & $21.00 \mathrm{~m}$ \\
\hline Breadth & $07.40 \mathrm{~m}$ \\
\hline Depth & $03.50 \mathrm{~m}$ \\
\hline Draft & $02.57 \mathrm{~m}$ \\
\hline Bhp and rpm & $500 \mathrm{bhp} @ 1500 \mathrm{rpm}$ \\
\hline Aux. Genset & $63 \mathrm{~kW} @ 2000 \mathrm{rpm}$ \\
\hline Displacement & $227.48 \mathrm{~T}$ \\
\hline Propeller & 3 blade \\
\hline
\end{tabular}

\section{b. $\quad$ Airborne Noise}

The airborne noise levels in $\mathrm{dB}$ (A) were measured using Bruel \& Kjaer handheld precision Sound Level Meter (SLM) type 2250 in Figure 4 with the specifications indicated in Table 2 of frequency range $6.3 \mathrm{~Hz}$ to $20 \mathrm{kHz}$. The SLM equipped with microphone and preamplifier. It is used for wide applications say FFT analysis, tone assessment, occupational health and safety assessment of $1 / 3$ octave and FFT methods using a software utility Holland and Wong (1995).

\section{c. Underwater Noise}

The underwater sound pressure levels measured using cetacean C57 hydrophone in Figure 4 with specifications indicated in Table 2, interfaced with TASCAM handheld PCM recorder for data acquisition and Spectra Plus Fast Fourier transformation software for converting the voltage signal to the time domain and frequency spectrum. 

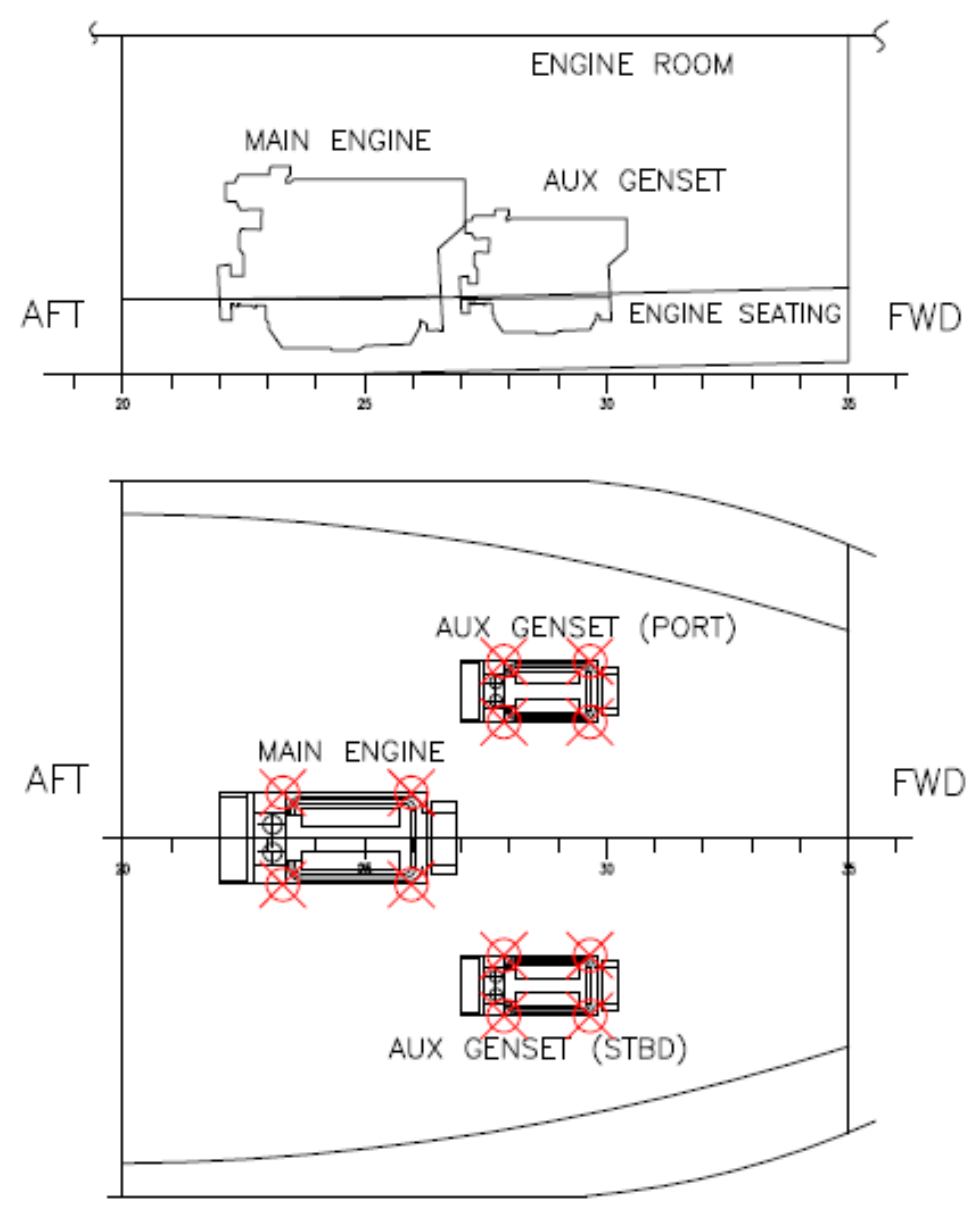

Figure 3: Measurement locations in the vessel engine room indicated in red color.

Table 2: Equipment specifications

\begin{tabular}{|l|c|c|c|}
\hline Specifications & Microphone B\&K 4189 & $\begin{array}{l}\text { Accelerometer } \\
\text { B\&K 4513 }\end{array}$ & $\begin{array}{l}\text { Hydrophone } \\
\text { C57 }\end{array}$ \\
\hline Frequency Range & $10 \mathrm{~Hz}$ to $10 \mathrm{kHz}$ & $1 \mathrm{~Hz}$ to $10 \mathrm{kHz}$ & 0.008 to 100 \\
\hline Reference Sensitivity & $47.8 \mathrm{mV} / \mathrm{Pa}$ & $1.030 \mathrm{mV} / \mathrm{ms}^{-2}$ & $-162 \mathrm{~dB} \mathrm{re} 1 \mathrm{~V} / \mu \mathrm{Pa}$ \\
\hline Maximum Operating Depth & - & - & $460 \mathrm{~m}$ \\
\hline
\end{tabular}

\section{$2.3 \quad$ Data processing}

All the measurement taken over the time duration basis during fishing vessels movement and vessel with auxiliary generators operating at the jetty. The B\&K PULSE software is used for sound and vibration measurement post-processing by enabling the scalable real-time signal FFT and overall analysis with IDA front end. The output of the hydrophone was recorded as the changes in the sound pressure levels (SPL) in wave file format. The wave format file is audio file in mp3 format. The sample frequency of the measured files being 192 $\mathrm{kHz}$ with 8192 FFT sample size. The power spectral density was calculated using a Hanning window with $75 \%$ overlap for all the datasets. Later Spectra plus-SC, Fast Fourier Transformation spectral analysis program is used to post-process the time domain signal to the frequency domain in 1/12 octave band. The post-processed spectrogram is used to identify the various excitation frequencies. 

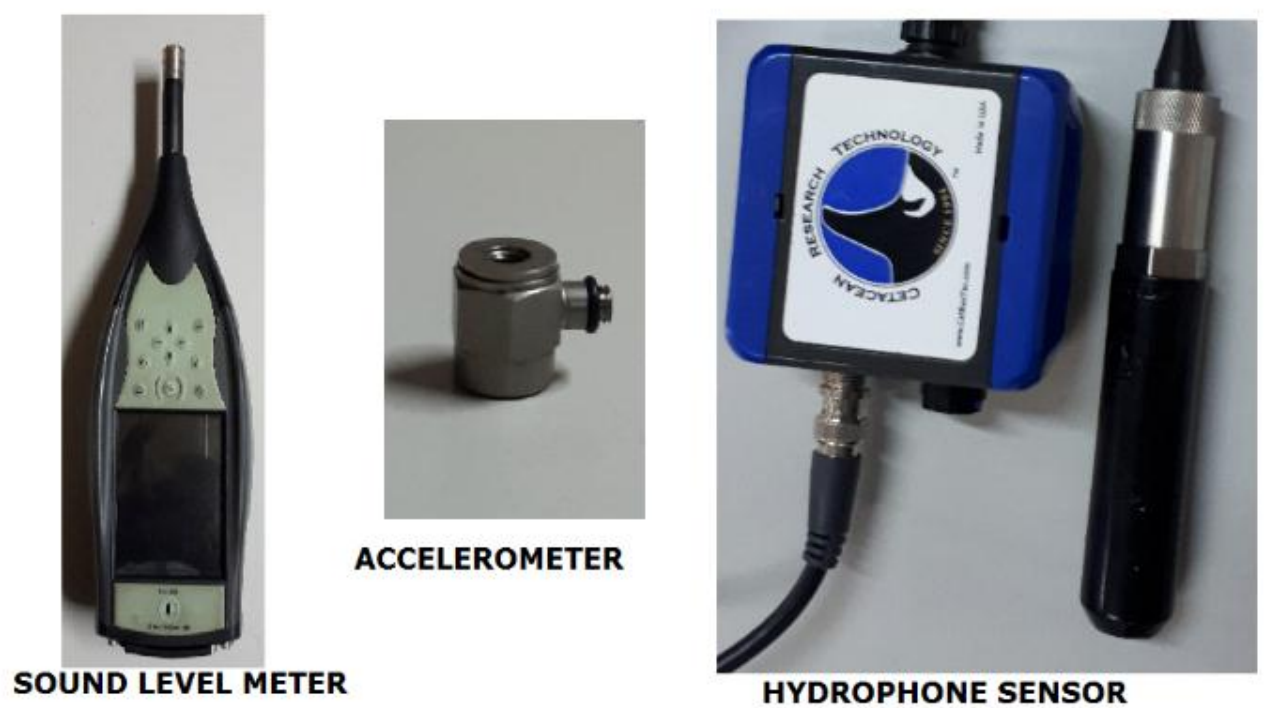

Figure 4: Sensors used for on-board measurements

\section{Results and Discussion}

The measurements helped to understand the influence of the underwater noise levels within the VFH limits due to the fishing vessel movements in relation to the vertical vibration levels and airborne noise levels. The VFH is a bay enclosed by breakwaters and with an opening as entrance on one side for ships to and from movement. The measurements were recorded during single fishing trawler vessel movement so as to avoid multiple sources for the same period of measurement.

The vertical vibration levels of the main engine and auxiliary Genset foundation as indicated in Figure 3 for four days along with the frequency are listed in the Table $3 \& 4$. The measured values of the foundation location are well within the acceptable criteria of ANSI and SNAME standards for ships (McGoldrick, 1960). All the measurement were taken are for the same vessel under similar conditions at the jetty operation condition.

Table 3: Vibration levels of Main Engine

\begin{tabular}{|c|c|c|c|c|c|c|c|c|}
\hline \multicolumn{9}{|c|}{ Name of Vessel: MV THARANGANI (FISHING TRAWLER) } \\
\hline \multicolumn{9}{|c|}{ VIBRATION MEASUREMENTS } \\
\hline \multirow{2}{*}{$\begin{array}{c}\text { S } \\
\text { No }\end{array}$} & \multirow[b]{2}{*}{ DATE } & \multirow{2}{*}{\multicolumn{2}{|c|}{ Location }} & \multicolumn{4}{|c|}{ 'V'VELOCITY mm/s } & \multirow{2}{*}{$\begin{array}{c}\text { ACCEPTABLE } \\
\text { CRITERIA ANSI S2.27 } \\
\text { (2002) and SNAME T\&R 2- } \\
\text { 29A (2004) }\end{array}$} \\
\hline & & & & $\begin{array}{c}\text { FREQ, } \\
\text { Hz }\end{array}$ & $\begin{array}{l}\text { PORT } \\
\text { 'V' }\end{array}$ & $\begin{array}{c}\text { FREQ, } \\
\text { Hz }\end{array}$ & $\begin{array}{l}\text { STBD } \\
\text { ' } \mathrm{V} \text { ' }\end{array}$ & \\
\hline 1 & \multirow{2}{*}{ 26.11.2018 } & \multirow{2}{*}{$\begin{array}{c}\text { MAIN } \\
\text { ENGINE }\end{array}$} & AFT & 704 & 0.19 & 704 & 0.331 & \multirow{8}{*}{$13 \mathrm{~mm} / \mathrm{s}$} \\
\hline 2 & & & FWD & 704 & 0.191 & 704 & 0.132 & \\
\hline 3 & \multirow{2}{*}{ 28.11.2018 } & \multirow{2}{*}{$\begin{array}{c}\text { MAIN } \\
\text { ENGINE }\end{array}$} & AFT & 704 & 0.213 & 704 & 0.274 & \\
\hline 4 & & & FWD & 704 & 0.187 & 704 & 0.213 & \\
\hline 5 & \multirow{2}{*}{ 29.11.2018 } & \multirow{2}{*}{$\begin{array}{c}\text { MAIN } \\
\text { ENGINE }\end{array}$} & AFT & 704 & 0.181 & 704 & 0.126 & \\
\hline 6 & & & FWD & 704 & 0.151 & 704 & 0.186 & \\
\hline 7 & \multirow{2}{*}{30.11 .2018} & \multirow{2}{*}{$\begin{array}{c}\text { MAIN } \\
\text { ENGINE }\end{array}$} & AFT & 704 & - & 704 & 0.19 & \\
\hline 8 & & & FWD & 704 & - & 704 & 0.331 & \\
\hline
\end{tabular}


Table 4: Vibration levels of Auxiliary Genset

\begin{tabular}{|c|c|c|c|c|c|c|c|c|}
\hline \multicolumn{9}{|c|}{ Name of Vessel: MV THARANGANI (FISHING TRAWLER) } \\
\hline \multicolumn{9}{|c|}{$\begin{array}{l}\text { VIBRATION MEASUREMENTS } \\
\end{array}$} \\
\hline \multirow{2}{*}{$\begin{array}{c}\text { S } \\
\text { No }\end{array}$} & \multirow{2}{*}{ DATE } & \multirow{2}{*}{\multicolumn{2}{|c|}{ Location }} & \multicolumn{4}{|c|}{ 'V'VELOCITY mm/s } & \multirow{2}{*}{$\begin{array}{c}\text { ACCEPTABLE } \\
\text { CRITERIA ANSI S2.27 } \\
\text { (2002) and SNAME T\&R 2- } \\
\text { 29A (2004) }\end{array}$} \\
\hline & & & & FREQ, & PORT & FREQ, & STBD & \\
\hline 1 & \multirow{2}{*}{ 26.11.2018 } & \multirow{2}{*}{$\begin{array}{c}\text { AUX. } \\
\text { GENSET } \\
\text { (PORT) }\end{array}$} & AFT & 832 & - & 832 & 1.86 & \multirow{8}{*}{$13 \mathrm{~mm} / \mathrm{s}$} \\
\hline 2 & & & FWD & 832 & - & 832 & 2.66 & \\
\hline 3 & \multirow{2}{*}{ 28.11.2018 } & \multirow{2}{*}{$\begin{array}{c}\text { AUX. } \\
\text { GENSET } \\
\text { (STBD) } \\
\end{array}$} & AFT & 832 & 0.187 & 832 & 0.213 & \\
\hline 4 & & & FWD & 832 & 2.14 & 832 & 1.25 & \\
\hline 5 & \multirow{2}{*}{ 29.11.2018 } & \multirow{2}{*}{$\begin{array}{c}\text { AUX. } \\
\text { GENSET } \\
\text { (PORT) }\end{array}$} & AFT & 832 & 1.61 & 832 & 1.09 & \\
\hline 6 & & & FWD & 832 & 1.65 & 832 & 3.13 & \\
\hline 7 & \multirow{2}{*}{30.11 .2018} & \multirow{2}{*}{$\begin{array}{c}\text { AUX. } \\
\text { GENSET } \\
\text { (PORT) }\end{array}$} & AFT & 832 & 0.238 & 832 & 0.326 & \\
\hline 8 & & & FWD & 832 & 1.64 & 832 & 2.2 & \\
\hline
\end{tabular}

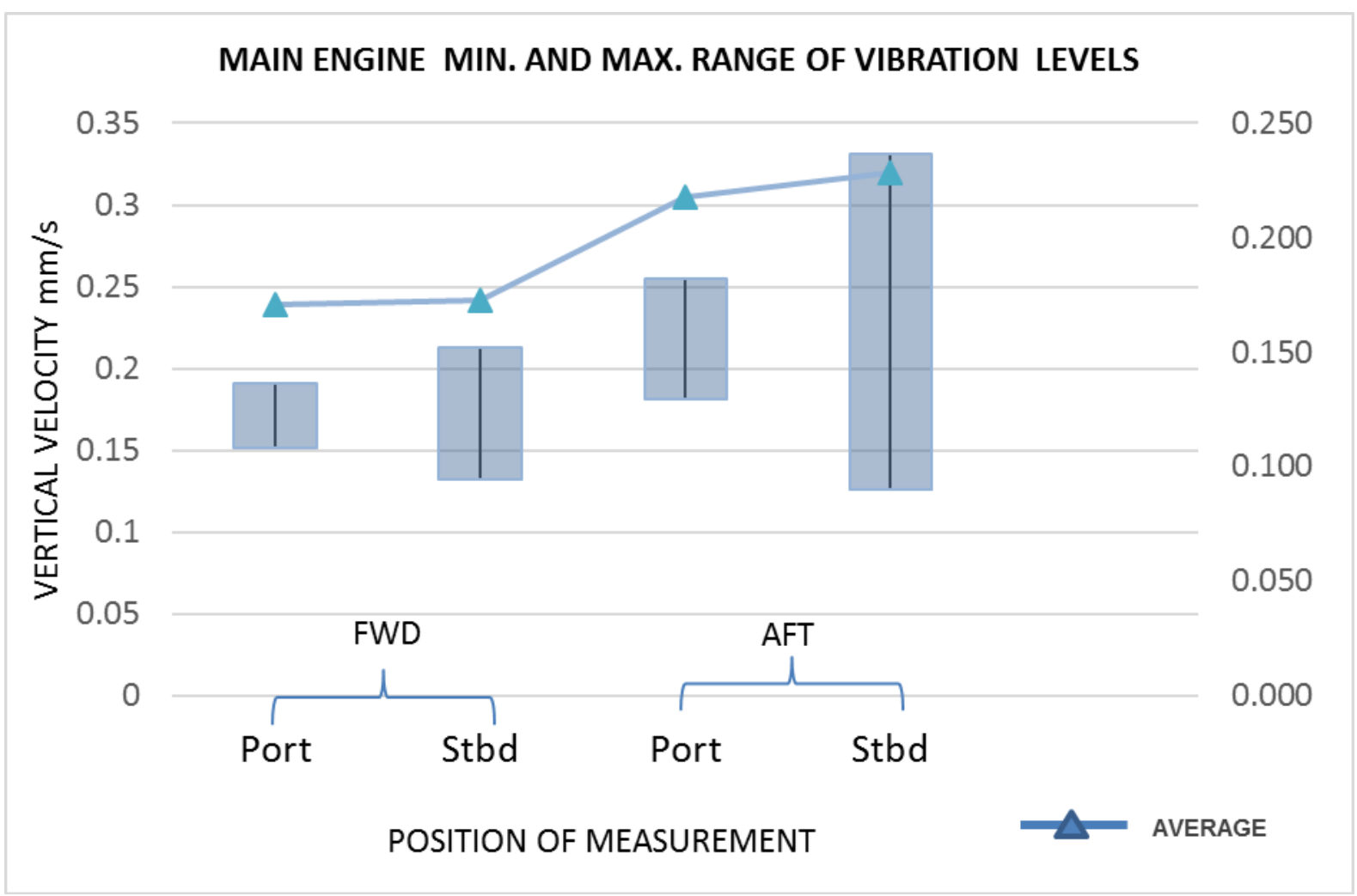

Figure 5: The main engine minimum and maximum range of vertical vibration levels as measured.

The vertical vibration levels of the main engine are found to be well within the acceptable criteria limits. The minimum and maximum range of the values is indicated in the Figure 5 showing an average value between $0.17-0.22 \mathrm{~mm} / \mathrm{s}$. It can be noticed that the aft of the main engine vibration levels is higher than the forward region, this may be due to the gearbox and shafting which are present in the aft of the main engine. The vibration levels range to the starboard side are larger than the port side, the possible reason is that the starboard machinery like auxiliary Genset, pumps etc. are in operation during the measurement. The vertical vibration levels of the auxiliary Genset are found to be well within the acceptable criteria limits. The minimum and maximum range of the values is indicated in the Figure 6 showing an average value between $0.7-3.1 \mathrm{~mm} / \mathrm{s}$. It 
can be noticed that the aft of the auxiliary Genset vibration level is slightly higher than the forward region, this may be due to the main engine which are present in the aft of the auxiliary Genset. Analyzing the vibration of the main engine that is converted into acoustic energy one should take into account the possibility of occurring of structural resonance. The underwater noise generated due to the main engine in operation indicates the peak responses in line with the vibration response as indicated in Figure 9. The trend of the peak responses in the frequency range $<3 \mathrm{kHz}$ indicated a close match with the vibration response peaks Grelowska et al (2013).

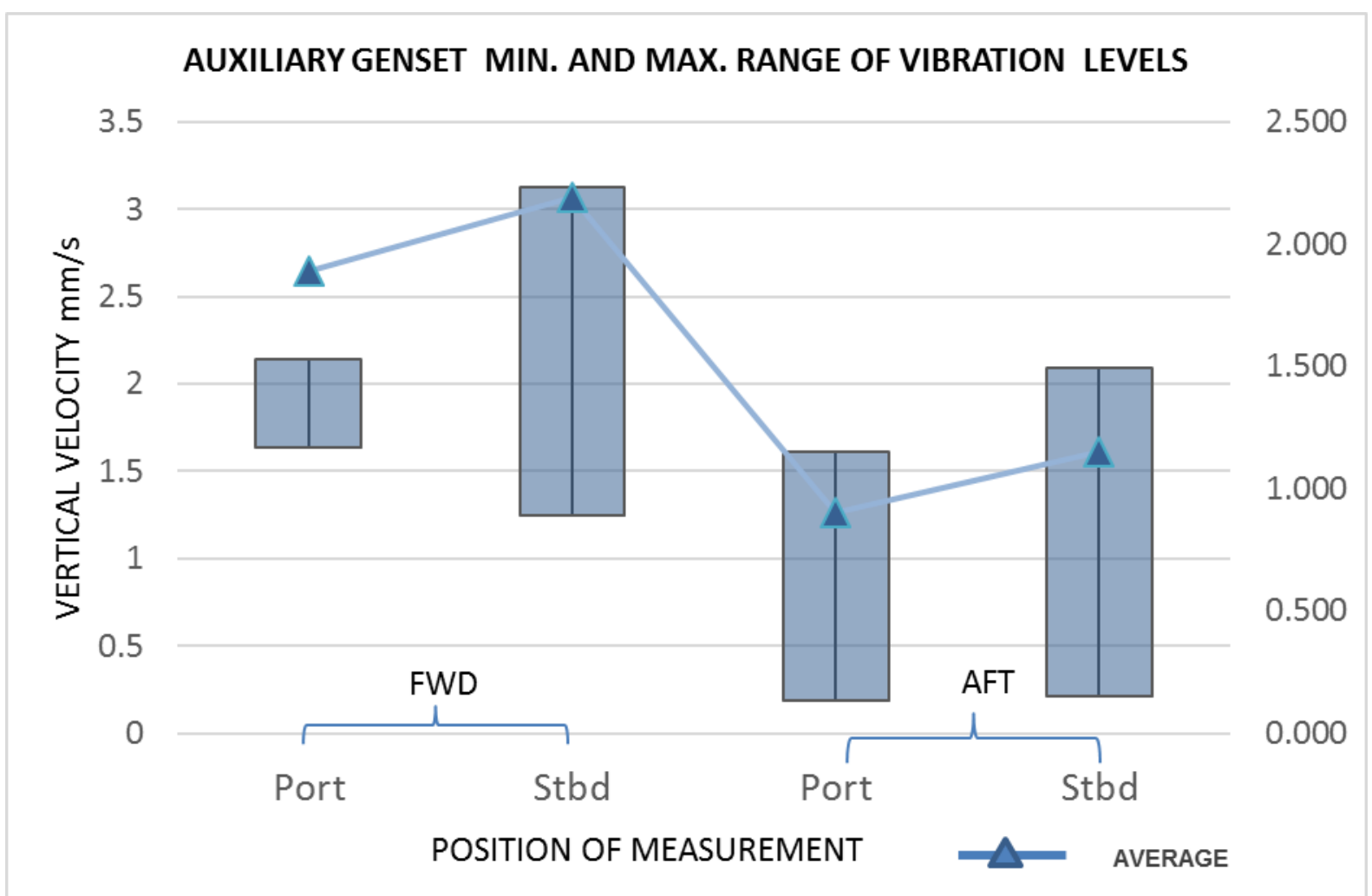

Figure 6: The Auxiliary Genset minimum and maximum range of vertical vibration levels as measured.

The vibration response spectrum of the main engine measured a peak response value of $0.25 \mathrm{~mm} / \mathrm{s}$ at frequency $704 \mathrm{~Hz}$ indicated in Figure 7 "A" and the auxiliary Genset measured a peak response value of $3.1 \mathrm{~mm} / \mathrm{s}$ at frequency $832 \mathrm{~Hz}$ indicated in Figure 7 "B". The main engine was operating at the jetty condition at 750 RPM and the auxiliary Genset was operating at $800 \mathrm{RPM}$. The underwater sound pressure levels in frequency domain measured a peak SPL of $162 \mathrm{~dB}$ re $1 \mu \mathrm{Pa}$ at frequency $1200 \mathrm{~Hz}$ indicated in Figure 8 "C". However, the underwater noise spectrogram shown in Figure 8 " $\mathrm{D}$ " indicate the disturbance due to the machinery in operation in the lower frequency range <3 kHz Barlett and Wilson (2002); (Gloza, 2011). The underwater noise generated due to the main engine in operation indicates the peak responses in line with the vibration response as indicated in Figure 9. The trend of the peak responses in the frequency range $<3 \mathrm{kHz}$ indicated a close match with the vibration response peaks.

The airborne noise levels indicated a peak sound pressure levels of $100 \mathrm{~dB}(\mathrm{~A})$ in the engine room when measured with the machinery in operation condition indicated in Figure 10 (Nilsson, 1978). 
(A)

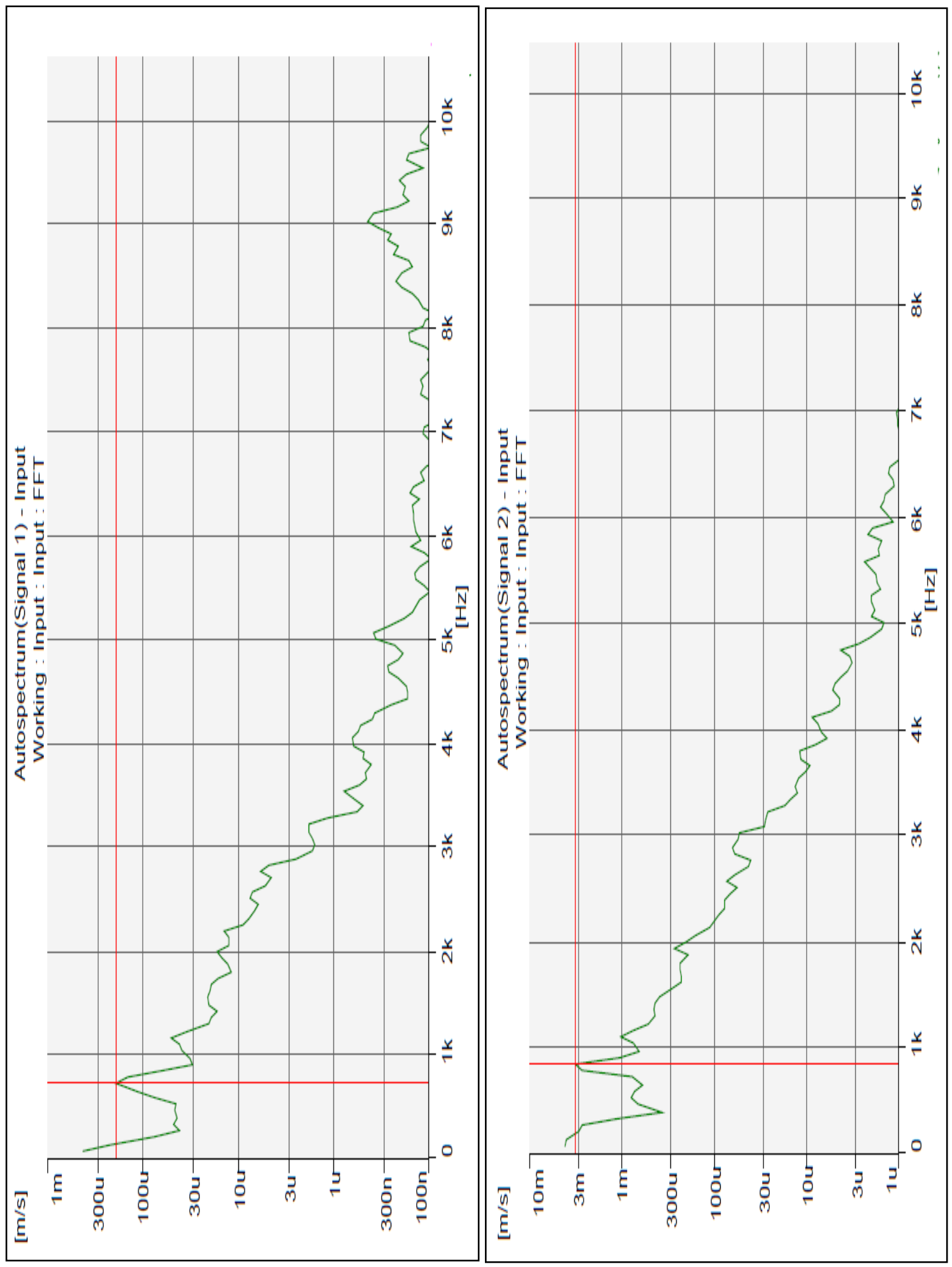

Figure 7: The vertical vibration spectrum (A) Maine Engine and (B) Auxiliary Genset

(B)

$|+|+\mid$ 
(C)

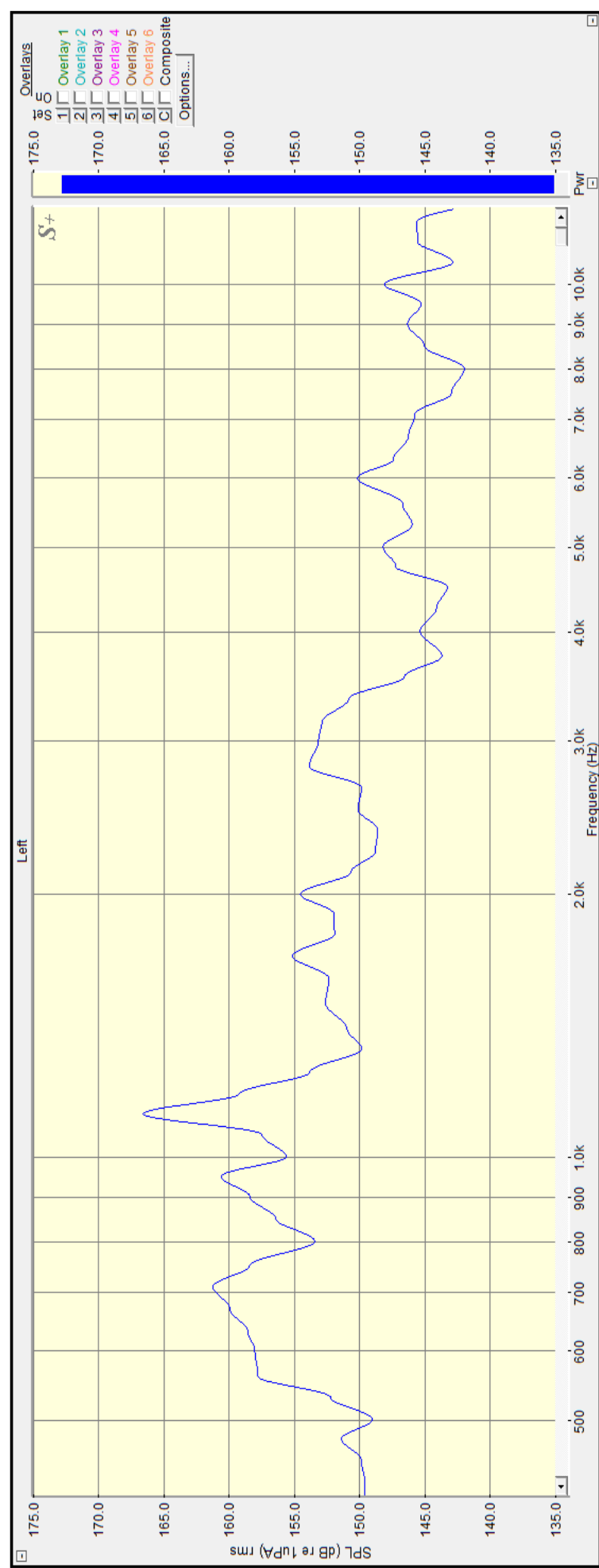

(D)

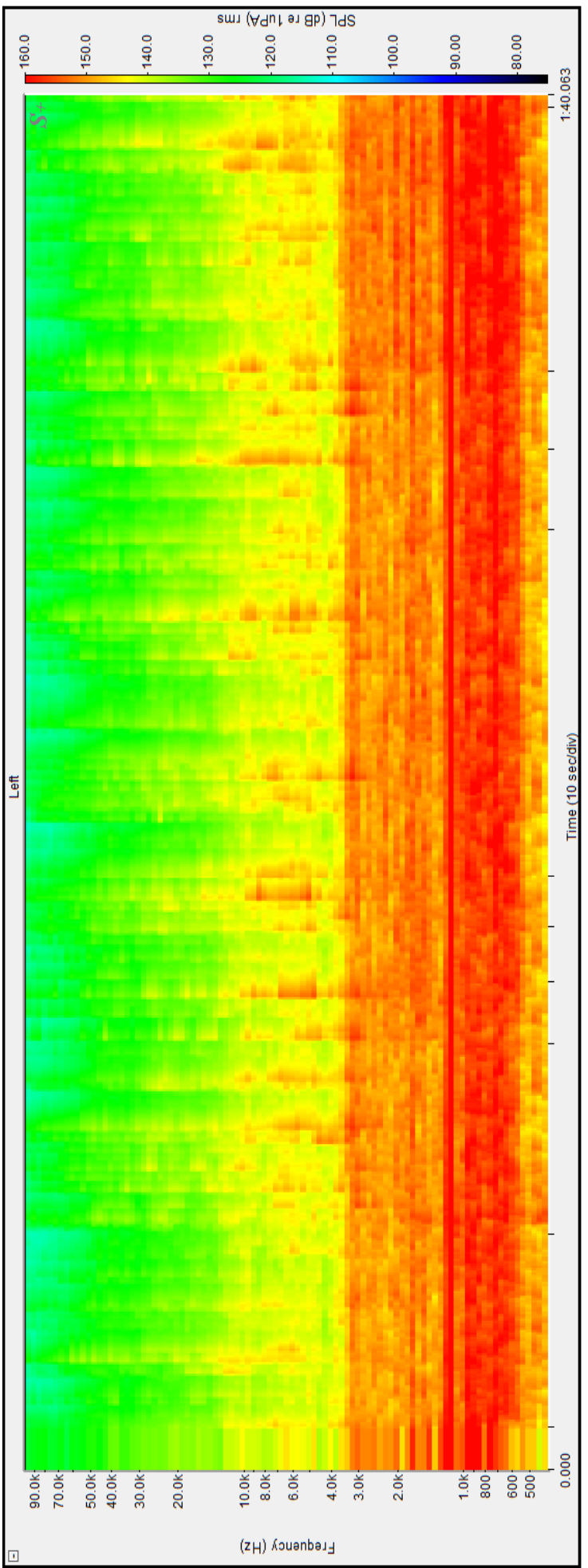

Figure 8: The underwater noise (C) Frequency spectrum and (D) Spectrogram 


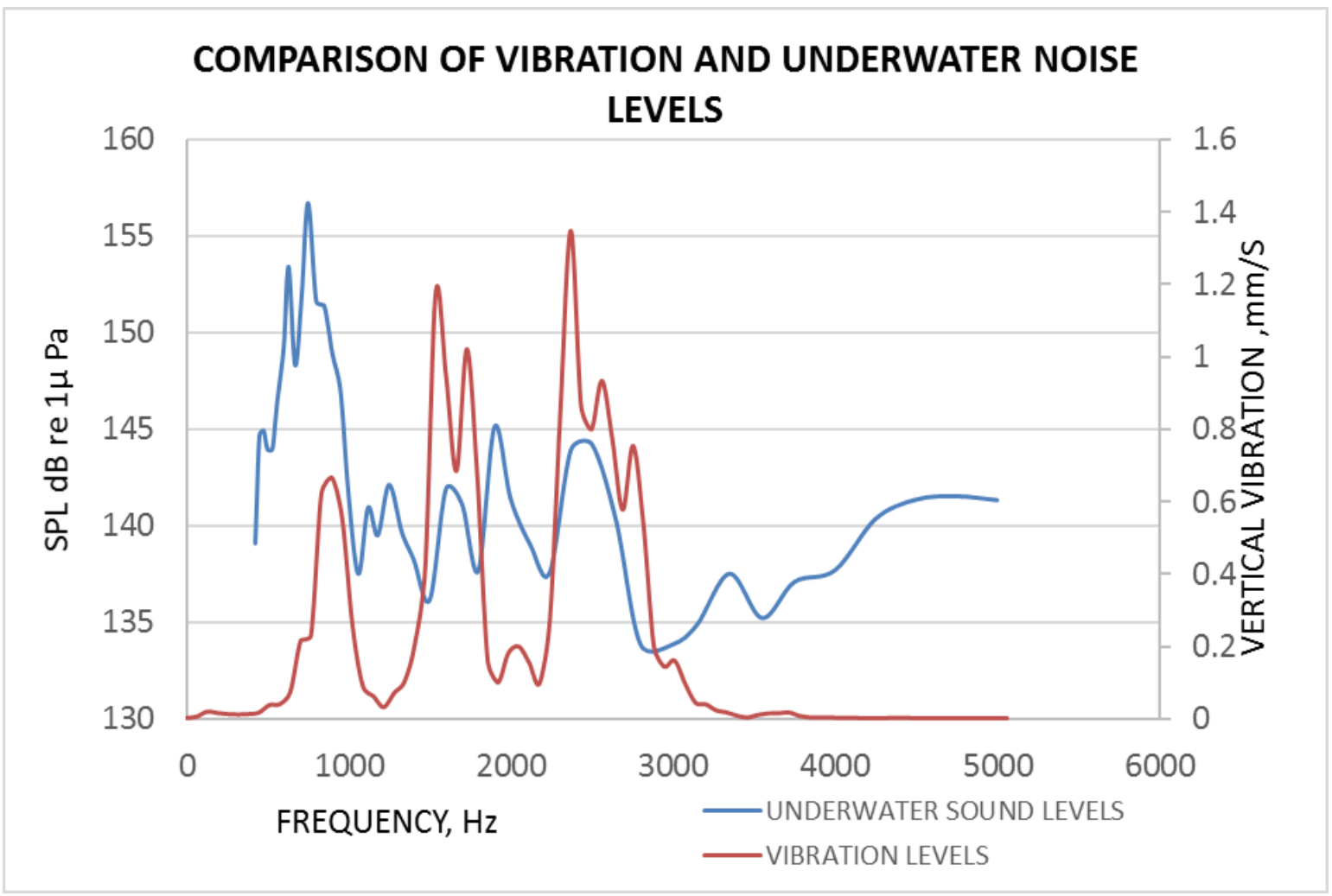

Figure 9: The comparison of the vertical vibration spectrum with the underwater noise spectrum
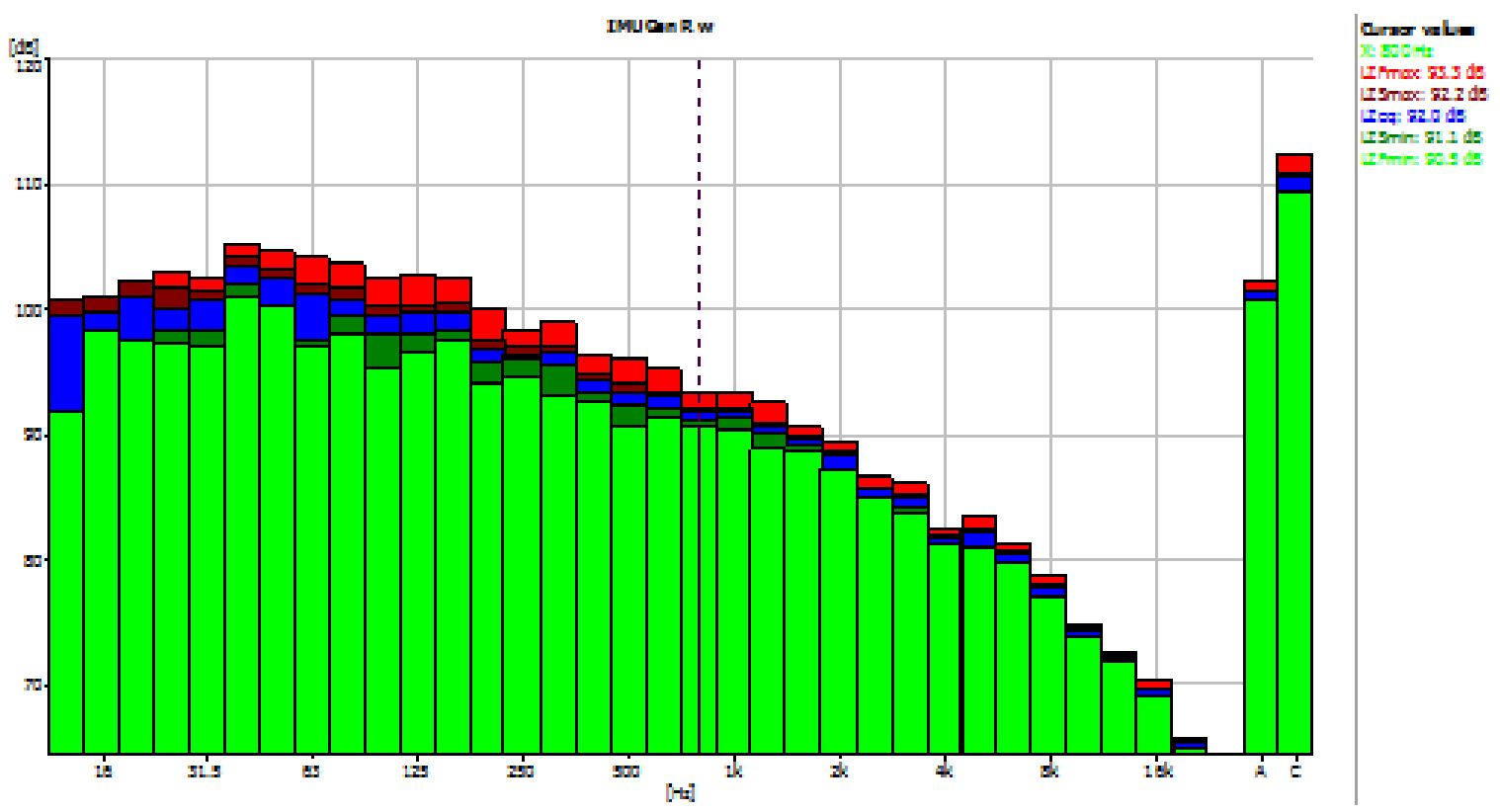

Figure 10: The airborne noise levels spectrum in the engine room 


\section{Conclusions}

The vessel radiation noise and vibration levels as measured are to be within the acceptable criteria limits and this has become a challenge to the designers. The measured data presented in this paper provide an indication of the underwater noise and vertical vibration levels of the fishing trawler during idling condition at the jetty with the main engine and auxiliary Genset in operation. The measurements are carried out in the Visakhapatnam fishing harbor because of easy access and being a busy harbor with more than 650 fishing boats operating on a continuous basis. The measurement also helped to investigate the machinery foundation mounting damping effects and to investigate the fishing vessel noise monitoring at the jetty. The continuous operation of a fishing vessel within the harbor limits greatly influence the ambient levels of the region. The results presented in this paper show that the radiated noise characteristics of a trawler under a jetty condition with main engine operating at 750 RPM indicated a peak vibration response of $0.331 \mathrm{~mm} / \mathrm{s}$ at $704 \mathrm{~Hz}$ and the auxiliary Genset operating at $800 \mathrm{RPM}$ indicated the peak vibration response of $3.31 \mathrm{~mm} / \mathrm{s}$ at $832 \mathrm{~Hz}$. The maximum and minimum range of vibration response for main engine was between $0.12-0.34 \mathrm{~mm} / \mathrm{s}$ and auxiliary Genset is $0.2-3.13 \mathrm{~mm} / \mathrm{s}$ at the foundation level. The hydrophone deployed on the side of the vessel measured underwater sound pressure level $166 \mathrm{~dB}$ re $1 \mu \mathrm{Pa}$ at frequency $1.2 \mathrm{kHz}$ due to the machinery in operation and spectrogram indicated the disturbance in the lower frequency $<3 \mathrm{kHz}$. Up on overlapping of the vibration and underwater noise levels on the same frequency axis, the disturbance of the peak levels is found to be overlapping at the same frequency indicating the disturbance due to the machinery activity. This will allow determining the components in the underwater noise sources. The airborne sound pressure levels in the engine room with machinery in operation indicated $100 \mathrm{~dB}$ (A) levels. All the measured values are found to be within the acceptable criteria limits as specified by various standards. However, the present results are measured for jetty conditions which are not applicable for comparison with standard but still found to be within limits.

Based on the measurements of the vibration, underwater noise and airborne noise, it is possible to estimate the source levels and very important for monitoring self-noise and the technical state of the ship mechanism. The underwater noise levels are influencing the ambient noise levels, especially in the low band frequency range within the vicinity of the harbor.

\section{Acknowledgment}

The data was collected from a Fishing trawler of Central Institute of Fisheries Nautical and Engineering Training (CIFNET), Visakhapatnam. We thank them for sharing the vessel during jetty operation which helped in understanding and studying the vibration, underwater noise and airborne levels of the vessel.

\section{Future Scope}

The present paper deals with the machinery vibration, underwater noise and airborne noise levels of fishing vessels as measured. This data is a useful resource for validation of the software models and carryout studies inrelation to vibration and underwater noise and noise propagation in water. The influence of machinery noise on the ambient levels can also be studied.

\section{References}

Aktas, B. (2015): Evaluation of a semi-empirical method for the propeller noise spectrum of a fisheries research vessel, International Congress on Sound and Vibration, Florence, Italy.

American Bureau of Shipping (2006): Guidance Notes on Ship Vibration, Houston, ABS Class.

Barlett, M. and Wilson, G. (2002): Characteristics of small boat signatures, Journal of Acoustical Society of America, Vol. 112, No. 5. https://asa.scitation.org/doi/10.1121/1.4778778

Bosschers, J. (2018): A semi-empirical prediction method for broadband hull-pressure fluctuations and underwater radiated noise by propeller tip vortex cavitation, Journal of Marine Science and Engineering, Vol. 6, No. 2, pp. 49.1-18. https://dx.doi.org/10.3390/jmse6020049

Brooker, A. and Humphrey, V. (2015): Measurement of radiated underwater noise from a small research vessel in shallow water. Journal of Ocean Engineering. 120. https://dx.doi.org/10.1016/j.oceaneng.2015.09.048

Carlton, J. S. and Vlasic, D. (2005): Ship vibration and noise: some topical aspects. 1st International Ship Noise and Vibration Conference: London: Lloyd's Register Technical Papers. 
Chung, K., Sutin, A., Sedunov, A. and Bruno, M. (2011): DEMON acoustic ship signaturemeasurements in an urban harbor, Journal of Advances in Acoustics and Vibration, Vol. 2011, pp. 1-13. http://dx.doi.org/10.1155/2011/952798

Gaggero, T., Rizzuto, E., Traverso, F. and Trucco, A. (2014): Comparing ship underwater noise measured at sea with predictions by empirical models, The 21st International Congress on Sound and Vibration, Beijing, China.

Gloza, I. (2011): Identification methods of underwater noise sources generated by small ships, Journal of Acoustic and Biomedical Engineering, Vol. 119, pp. 961-965. https://dx.doi.org/10.12693/APhysPolA.119.961

Grelowska, G., Kozaczka, E., Kozaczka, S. and Szymczak, W. (2013): Underwater noise generated by a small ship in the shallow sea. archives of aacoustics, Vol. 38, No. 3, pp. 351-356. https://dx.doi.org/10.2478/aoa-2013$\underline{0041}$

Holland, C. G. and Wong, S. F. (1995): Noise prediction and correlation with full scale measurements in ships, Transactions of Institute of Marine Engineers (IMarE), Vol. 107, No. 3, pp. 195-207.

IQOE (2016): International Quiet Ocean Experiment. https://www.iqoe.org, accessed on 1 Sept. 2016.

Lurton, X. (2010): An Introduction to Underwater Acoustics, Springer-Verlag, Berlin, Germany \& Praxis Publishig, UK .

McGoldrick, R. T. (1960): Ship Vibration, Technical Report No. 1891, Washington DC: DTMB, USA

MEPC1 circular 833. (2014): IMO Marine Environmental Protection Committee. https://docs.imo.org/Category.aspx?cid=108, accessed on 1 Sept. 2016.

Mitson, R.B. (1995): Underwater noise of research vessels, Denmark: ICES, Coopertive Research Report No. 209, UK.

Nilsson, A. C. (1978): Noise prediction and prevention in ships, Ship Vibration Symposium, Artington: SNAME, USA.

Ozsoysal, Reyhan. (2004): A Review of recent ship vibration papers, The Shock and Vibration Digest, Vol. 36, pp. 207-214. https://dx.doi.org/10.1177/0583102404038874

Kumar, G.V.V.P, Prasad, V.V.S. and Ramesh, U.S. (2019): Underwater noise radiated by fishing vessels in Visakhapatnam fishing harbor, Journal of Offshore Structure and Technology, Vol. 6, No. 1, pp. 28-38.

Kuma, G.V.V.P, Prasad, V.V.S. and Ramesh, U.S. (2019): Underwater noise levels in Indian waters of the coast of Mormugao port, Journal of Operational Oceanography, Vol.12, No. 1, pp. 1-12.

https://dx.doi.org/10.1080/1755876X.2019.1632665

Putland, R., Merchant, N., Farcas, A. and Radford, C. (2018): Vessel noise cuts down communication space for vocalizing fish and marine mammals. Wiley Global Change Biology, pp. 1708-1721.

https://dx.doi.org/10.1121/1.5036178

Tratch, J. (2005): Vibration Transmission through Machinery Foundation and Ship Bottom Structure, PhD thesis, Department of Mechanical Engineering, MIT, USA. 